\title{
Numerical investigation on the interlayer surface strength effects in carbon/epoxy composite laminates subjected to low-velocity impact
}

\author{
Xiaojun Tang ${ }^{a,}$, Pengbo Yin ${ }^{b}$, Tianli Hui ${ }^{c}$, Wentao Yu ${ }^{d}$ and Fenglong Yang ${ }^{e}$ \\ Beijing Spacecrafts, China Academy of Space Technology, Beijing 100094, China \\ axiaojuntang87@sina.com, ${ }^{\mathrm{b}}$ pengboyin2013@163.com, chuitianl@sina.com, ${ }^{\mathrm{d}}$ wentaoy@aliyun.com, ${ }^{\mathrm{e}} \mathrm{fe}$ \\ nglongy@sina.com \\ *corresponding author: Xiaojun Tang
}

Keywords: interlayer surface strength, carbon/epoxy composite, low-velocity impact, surfacebased cohesive behaviour

\begin{abstract}
The Hashin failure model and the 3D progressive damage method-based user material subroutine are employed to characterize the impact damage characteristics of composite layer, and surface based cohesive behaviour are introduced to characterize the interlaminar mechanical property in this paper. The dynamic response process of the carbon/epoxy composite laminates subjected to low-velocity impact load under different interlayer surface strength conditions are simulated, and the effects of interlayer interface strength on the ballistic property of composite materials are emphatically analysed. Results show that the impact dynamic response of composite laminated plates is a process of stress waves propagation, reflection, and interference between layer and layer. The kinetic energy dissipation of bullet varies depending on the interlayer surface strength of carbon/epoxy composite laminates. The kinetic energy absorbing performance of carbon/epoxy composite laminates is directly altered by the interlayer surface strength. The interlayer surface strength of laminates also directly impacts of the elastic strain energy carbon/epoxy composite and the kinetic energy dissipation of bullet in laminates failure. Namely, the transformed form of the bullet kinetic energy is affected by the interlayer surface strength significantly. In general, the interlayer surface strength presents a significant role on whether the failure form, the contact force, the kinetic energy dissipation process, the elastic strain energy composite laminates or the kinetic energy dissipation of bullet in laminates failure during the impact process.
\end{abstract}




\section{Introduction}

The composite materials are widely used in many industry and engineering fields, due to its excellent mechanical properties, physical properties and light properties. Composites can be divided into many different categories according to composition and preparation form, etc., and composite material laminates are the most widely used composite materials in engineering, especially in aerospace. In the actual use of composite materials, it is found that the interface is an important factor in the strength of composite material laminates. The interfacial phase of the composite material laminates includes the interface phase between the enhanced phase and the matrix, which is the same as the interface phase between the layers. It is the bridge of stress transfer in the composite material laminates. The interface phase between enhanced phase and matrix phase plays the role of stress transfer between enhanced phase and matrix, and then the interlayer interface plays the role of stress transfer between the layers; meanwhile the interface phase also plays an important role in the block damage expansion. In recent years, the research on interface mechanics performance and its modification is the frontier direction in the mechanical properties research of composite materials.

The properties and damage behavior of the composite material laminates interface phase are studied by many scholars[1-5]. Some scholars studied the interface stress transfer characteristics of resin matrix composite between the fiber reinforced phase and matrix under thermal-load conditions using experiment and simulation analysis method, and found that the surface shear stress is in a parabola distribution. The embedding end of the fiber is very important in the stress transfer, and the interface failure appears firstly, and then interfacial residual stress induced heat load can reduce the stress concentration of the fibre embedding end[4]. The energy release rate of the interlayer interface between composite layers was studied considering the lateral shear effect by Luo, etc.[5]. A new type zero-thickness interface unit model characterized the constitutive relation, the damage criterion and the damage evolution characteristics is established by Guan, and found that the damage analysis model of the composite material layer can be used to simulate the expansion of the crack-I[6]. The interlamination fracture properties of composites under wet and heat environment (material absorption and environmental temperature) were studied by Guan, and found that the effect of moisture absorption on the t300/5405 composite material is tiny, and the fracture toughness of the interlamination increased significantly with the increase of moisture absorption in the high temperature environment[7]. The extension of the interlamination damage of the composite material laminates under crosswise load is investigated using finite element simulation by Nishikawa[8]. From these efforts, it is obtained that the interface characteristics are different, the composite laminate is different, and its failure modes can be significantly different. Actually, most of these investigations focused on composite material interface enhance, interface modification, interface mechanical properties characterization, interface strength mechanics performance experiment or simulation study, and few studies have focused on the effect of interlayer interface characteristics on the ballistic property of composite materials. While it is believed that the strength of interlayer interface has a significant effect on the stress transfer, damage transmission path and failure mode of the composite material, there is reason to believe that the strength of interlayer interface plays an important role in the dynamic response of composite laminates under lowvelocity impact.

Therefore, the 3D progressive damage analysis-based user material subroutine and the surface based cohesive behavior are introduced, and the dynamic response process of carbon/epoxy composite laminates subjected to low-velocity impact load under different interlayer surface strength conditions is simulated using Abaqus finite element software. The effects of interlayer interfacial strength on the ballistic property of composite materials are analyzed in this paper. 


\section{Calculation model}

\subsection{Physical model}

The physical model is shown in figure 1(a). The composite laminates are laid according to $\left[\mathrm{C}_{0} \mathrm{C}_{90}\right]_{6}$ cross-ply methods, namely $0^{\circ}$ and $90^{\circ}$ fibre lay alternately. $0^{\circ}$ and $90^{\circ}$ layer are 6 layers each, there will be 12 layers. The thickness of each layer is equal to $0.2 \mathrm{~mm}$, and the total thickness is equal to $2.4 \mathrm{~mm}$. the target (namely, the composite laminates) size is length $(\mathrm{X}) \times$ width $(\mathrm{Y}) \times$ thickness (Z) is equal to $50 \mathrm{~mm} \times 50 \mathrm{~mm} \times 3 \mathrm{~mm}$. The bullet is a rigid sphere with a diameter of $5.55 \mathrm{~mm}$. The composite laminates geometry centre is simulated as the impact position in this paper, and the fixed end boundary condition is forced to the four sides of the composite laminates. The material properties and strength parameters of composite laminates are shown in table 1 and table 2, respectively. The "1" in the table is the direction of the fibres, namely it is the X direction. The "2" and "3" are respectively refers to the vertical direction of the fibres in the surface of the laminate and the vertical direction of the fibres in the thickness direction, which is the $\mathrm{Y}$ and the $\mathrm{Z}$ direction respectively. $S_{12}, S_{13}, S_{23}$ are shear strength in the corresponding direction, and $X_{T}, X_{C}, Y_{T}, Y_{C}$, $\mathrm{Z}_{\mathrm{T}}, \mathrm{Z}_{\mathrm{C}}$ respectively are the tensile strength of the fibre direction, the compression strength of the fibre direction, the matrix of the tensile strength within plane, compression strength within plane, the matrix tensile layer strength along thickness direction, compression strength along thickness direction. In the process of grid partitioning, a relatively sparse grid node is placed in the noncentral location of the composite laminate; meanwhile the grid nodes are gathered near the central region in order to keep precision and computing efficiency. The mesh type of composite laminates and bullet both is the C3D8R unit.

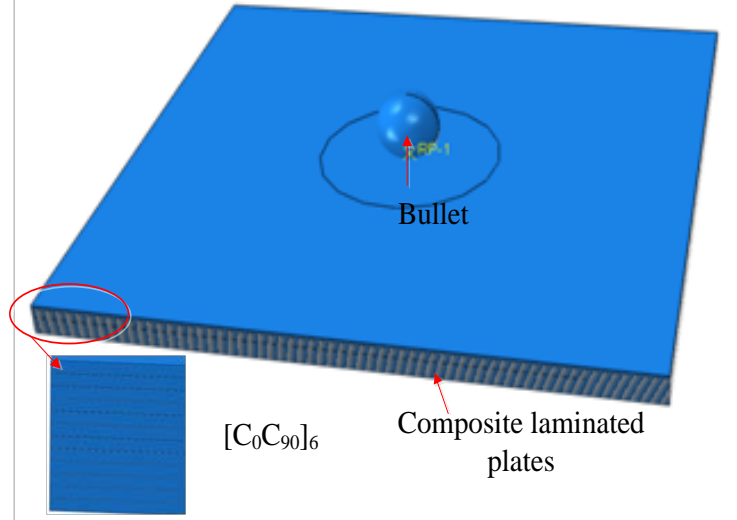

(a) Computational model

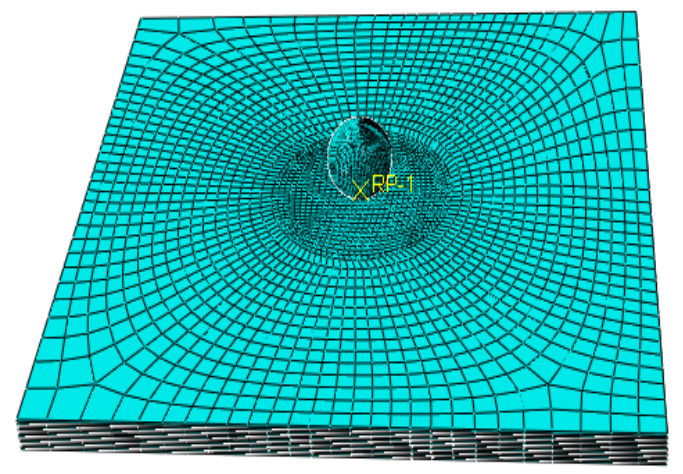

(b) Mesh

Fig.1 Computational model and mesh

Table.1 Unidirectional stiffness parameters for composite laminate

\begin{tabular}{|c|c|c|c|c|c|c|c|c|}
\hline $\mathrm{E}_{11}(\mathrm{Gpa})$ & $\mathrm{E}_{22}(\mathrm{Gpa})$ & $\mathrm{E}_{33}(\mathrm{Gpa})$ & $\mathrm{G}_{12}(\mathrm{Gpa})$ & $\mathrm{G}_{13}(\mathrm{Gpa})$ & $\mathrm{G}_{23}(\mathrm{Gpa})$ & $\mathrm{v}_{12}$ & $\mathrm{v}_{13}$ & $\mathrm{~V}_{23}$ \\
\hline 164.7 & 9.9 & 9.9 & 5.61 & 5.61 & 5.61 & 0.325 & 0.325 & 0.325 \\
\hline
\end{tabular}

Table.2 Material strength parameters for composite laminate

\begin{tabular}{|c|c|c|c|c|c|c|c|c|}
\hline $\mathrm{X}_{\mathrm{T}}(\mathrm{MPa})$ & $\mathrm{X}_{\mathrm{C}}(\mathrm{MPa})$ & $\mathrm{Y}_{\mathrm{T}}(\mathrm{MPa})$ & $\mathrm{Y}_{\mathrm{C}}(\mathrm{MPa})$ & $\mathrm{Z}_{\mathrm{T}}(\mathrm{MPa})$ & $\mathrm{Z}_{\mathrm{C}}(\mathrm{MPa})$ & $\mathrm{S}_{12}(\mathrm{MPa})$ & $\mathrm{S}_{13}(\mathrm{MPa})$ & $\mathrm{S}_{23}(\mathrm{MPa})$ \\
\hline 2562 & 1961 & 80 & 389 & 80.3 & 389 & 110 & 110 & 156.8 \\
\hline
\end{tabular}

\subsection{Failure characterization method}

\subsubsection{Hashin failure mode}

Hashin failure model is introduced to characterize the fiber tensile failure, the compression failure, the matrix tensile failure and matrix compress failure in plane as well as the matrix failure along thickness direction in the impact process. The Hashin failure model can be expressed as follows: 
Fiber tensile failure:

$$
e_{f t}^{2}=\left(\frac{\sigma_{11}}{X_{t}}\right)^{2}+\left(\frac{\sigma_{12}}{S_{12}}\right)^{2}+\left(\frac{\sigma_{13}}{S_{13}}\right)^{2} \geq 1
$$

Fiber compress failure:

$$
e_{f c}^{2}=\left(\frac{\sigma_{11}}{X_{t}}\right)^{2} \geq 1
$$

Matrix tensile failure in plane:

$$
e_{f t}^{2}=\left(\frac{\sigma_{11}}{Y_{t}}\right)^{2}+\left(\frac{\sigma_{12}}{S_{12}}\right)^{2}+\left(\frac{\sigma_{23}}{S_{23}}\right)^{2} \geq 1
$$

Matrix compress failure in plane:

$$
e_{f c}^{2}=\left(\frac{\sigma_{22}}{Y_{t}}\right)^{2} \geq 1
$$

Matrix tensile failure in z-axis:

$$
e_{d t}^{2}=\left(\frac{\sigma_{33}}{Z_{t}}\right)^{2}+\left(\frac{\sigma_{23}}{S_{23}}\right)^{2}+\left(\frac{\sigma_{13}}{S_{13}}\right)^{2} \geq 1
$$

Matrix compress failure in z-axis:

$$
e_{d c}^{2}=\left(\frac{\sigma_{23}}{S_{23}}\right)^{2}+\left(\frac{\sigma_{13}}{S_{13}}\right)^{2} \geq 1
$$

\begin{tabular}{|c|c|c|c|c|c|c|c|c|c|}
\hline $\begin{array}{l}\text { Material parameters } \\
\text { Failure mode }\end{array}$ & $\mathrm{E}_{11}$ & $\mathrm{E}_{22}$ & $\mathrm{E}_{33}$ & $\mathrm{G}_{12}$ & $\mathrm{G}_{13}$ & $\mathrm{G}_{23}$ & $\mu_{12}$ & $\mu_{13}$ & $\mu_{23}$ \\
\hline Fiber tensile failure & 0.1 & - & - & 0.1 & 0.1 & - & 0.1 & 0.1 & - \\
\hline Fiber compress failure & 0.2 & - & - & 0.2 & 0.2 & - & 0.2 & 0.2 & - \\
\hline Matrix tensile failure in plane & - & 0.1 & - & 0.1 & - & 0.1 & 0.1 & - & 0.1 \\
\hline Matrix compress failure in plane & - & 0.2 & - & 0.2 & - & 0.2 & 0.2 & - & 0.2 \\
\hline Matrix tensile failure in $\mathrm{z}$ direction & - & - & 0.1 & - & 0.1 & 0.1 & - & 0.1 & 0.1 \\
\hline Matrix compress failure in $\mathrm{z}$ direction & - & - & 0.2 & - & 0.2 & 0.2 & - & 0.2 & 0.2 \\
\hline
\end{tabular}

When any formulas in the above are established, the composite material layer will have the corresponding failure damage. According to the principle of progressive damage, the corresponding material stiffness degradation will be carried out. The material stiffness degradation rule is shown in table 3 .

Table.3 Stiffness degradation rule in VUMAT

\subsubsection{Surface based cohesive behavior}

The cohesion model was developed by Barenblatt[9] and Dugdale[10] in the 1960s. It is a traction separation constitutive model, and the stress-strain relationship between the materials and the interface phase is established through the relationship between the cohesion relations. This model assumes that it is subject to the linear elastic stress-separation criteria before the damage appearing, and the interface property parameters are characterized in the mixed functions of the normal and tangential deformation of the interface phase. It is thought that the failure behavior of the interface is the process with the gradual degeneration of the interface stiffness, and the model can be used directly in the stress-separation form to characterize the interface decohesion behavior in the material.

From the foreword, in addition to being highly relevant between composite laminated board mechanical properties and the material properties of the various layers, laminated plates interlayer 
interface properties in determining the mechanical properties of the laminated plates plays an important role.

Therefore, in this paper, the cohesive model is used to represent the interlayer surface behavior of composite materials. It is known that the cohesive model includes the solid element based cohesive model and the surface based cohesive behavior. Considering the surface based cohesive behavior needn't real element, there is no interface unit that attaches to the surface of the bullet and causes the unit to be extremely distorted so that makes the calculation difficult to converge. Therefore surface based cohesive behavior is introduced in this paper. Table.4 shows the cohesive interface parameters for composite laminates.

Table.4 Cohesive interface parameters for composite laminates[11]

\begin{tabular}{|c|c|c|c|c|c|c|c|c|}
\hline \multicolumn{3}{|c|}{ Stiffness $(\mathrm{GPa} / \mathrm{m})$} & \multicolumn{3}{c|}{ Strength $(\mathrm{MPa})$} & \multicolumn{3}{c|}{ Critical strain energy release rate $\left(\mathrm{J} / \mathrm{m}^{2}\right)$} \\
\hline $\mathrm{K}_{\mathrm{N}}=120000$ & $\mathrm{Ks}=43000$ & $\mathrm{Kt}=43000$ & $\mathrm{~N}=30$ & $\mathrm{~S}=80$ & $\mathrm{~T}=80$ & $\mathrm{G}_{\mathrm{IC}}=520$ & $\mathrm{G}_{\text {IIC }}=970$ & $\mathrm{G}_{\text {IIIC }}=970$ \\
\hline 2562 & 1961 & 80 & 389 & 80.3 & 389 & 110 & 110 & 156.8 \\
\hline
\end{tabular}

\section{Results and discussion}

The progressive damage analysis-based user material subroutine and the surface based cohesive behavior are introduced to simulate the dynamic response process of carbon/epoxy composite laminates subjected to low-velocity impact load under different interlayer surface strength conditions in this paper. The interlayer surface strength conditions (9 cases) are shown in table 1. Fig.2 shows the stress evolution of the upper layer of the carbon/epoxy composite laminates for case $1\left(\right.$ Stre/Stre $\left._{0}=1\right)$ under the impact energy of 10J. Fig. 2(a), (b), (c), (d), (e) and (f) are corresponding to $3.0014 \times 10^{-5} \mathrm{~s}, 9.0007 \times 10^{-5} \mathrm{~s}, 5.1000 \times 10^{-4} \mathrm{~s}, 1.0200 \times 10^{-3} \mathrm{~s}, 1.5000 \times 10^{-3} \mathrm{~s}$ and $3.000 \times 10^{-3} \mathrm{~s}$, respectively. The direction of the upper carbon fiber layer is $0^{\circ}$, and the direction definition is shown in figure 2(a). The stress evolution process of the upper layer in the whole impact process is found from the figure. The stress distribution along the fiber direction is significantly different from that along the matrix direction, and the stress wave propagation in the fiber direction is also significantly faster than that in the matrix direction. It also can be seen that the stress of the upper layer of composite laminates in local area is relatively large while the stress between the areas with lager stress is relatively small. It is believed that this is because, under the impact of a bullet, the composite laminated plates produce the compressive stress waves first and then spread quickly around. When the compressive stress wave passed to the laminates boundary, it will be reflected, and the tensile stress waves will be induced. The encounter between the tensile stress wave and the compressive stress wave will form a low-stress area. After the impact, the laminates are penetrated, and there is still residual stress distribution around the damage area.

Table 4 the interface strength cases

\begin{tabular}{|c|c|c|c|c|}
\hline \multicolumn{2}{|c|}{ Case/ (Stre/Stre $)$} & \multicolumn{3}{|c|}{ Strength (MPa) } \\
\hline Case1[11] & 1 & $\mathrm{~N}=30$ & $\mathrm{~S}=80$ & $\mathrm{~T}=80$ \\
\hline Case2 & 1.25 & $\mathrm{~N}=37.5$ & $\mathrm{~S}=100$ & $\mathrm{~T}=100$ \\
\hline Case3 & 1.4 & $\mathrm{~N}=42$ & $\mathrm{~S}=112$ & $\mathrm{~T}=112$ \\
\hline Case4 & 1.5 & $\mathrm{~N}=45$ & $\mathrm{~S}=120$ & $\mathrm{~T}=120$ \\
\hline Case5 & 1.6 & $\mathrm{~N}=48$ & $\mathrm{~S}=128$ & $\mathrm{~T}=128$ \\
\hline Case6 & 1.75 & $\mathrm{~N}=52.5$ & $\mathrm{~S}=140$ & $\mathrm{~T}=140$ \\
\hline Case7 & 2.0 & $\mathrm{~N}=60$ & $\mathrm{~S}=160$ & $\mathrm{~T}=160$ \\
\hline
\end{tabular}




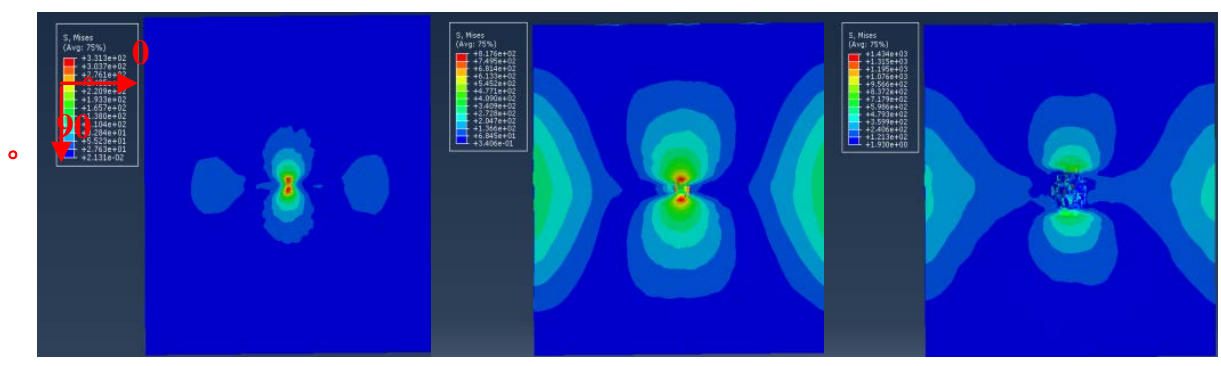
(a) $3.0014 \times 10^{-5} \mathrm{~s}$
(b) $9.0007 \times 10^{-5} \mathrm{~s}$
(c) $5.1000 \times 10^{-4} \mathrm{~s}$
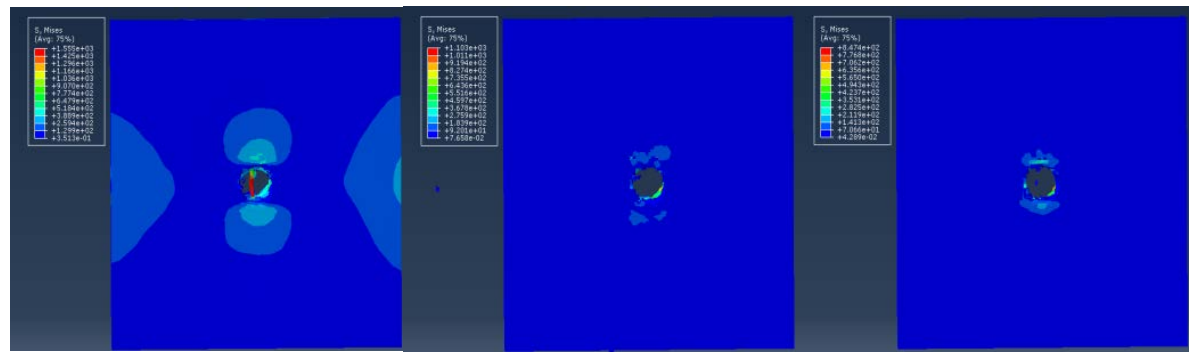

(d) $1.0200 \times 10^{-3} \mathrm{~S}$

(e) $1.5000 \times 10^{-3} \mathrm{~s}$

(f) $3.000 \times 10^{-3} \mathrm{~s}$

Fig.2 The stress evolution of the carbon/epoxy composite laminates under the impact energy of 10J

Fig.3 shows the deformation and damage of the carbon/epoxy composite laminates under for different cases. Fig. 3(a), (b), (c), (d), (e) and (f) are corresponding to Stre/Stre ${ }_{0}=1.0,1.25,1.4,1.5$, 1.75 and 2.0, respectively. From the figure, there is a significant difference in the form of the composite material failure under the different interface strength cases, which indicates the interlayer interface strength has a significant effect on the failure modes and the stress transfer between composite layers.

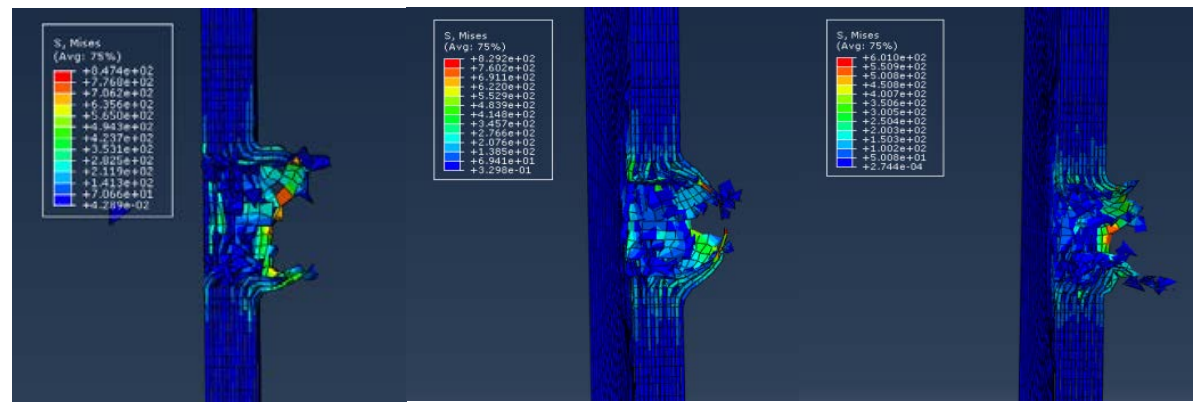

(a) 1.0

(b) 1.25

(c) 1.4

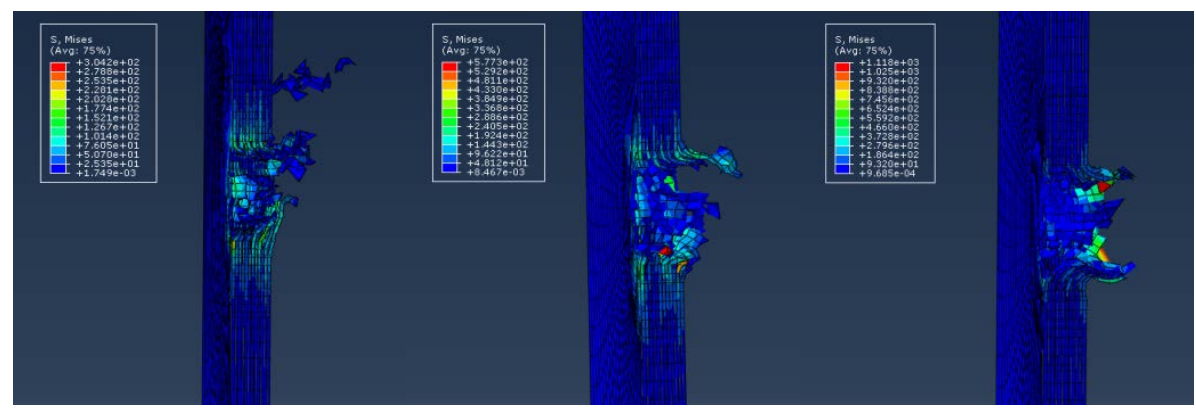
(d) 1.5
(e) 1.75
(f) 2.0

Fig.3 Deformation and damage of the carbon/epoxy composite laminates under for different cases 


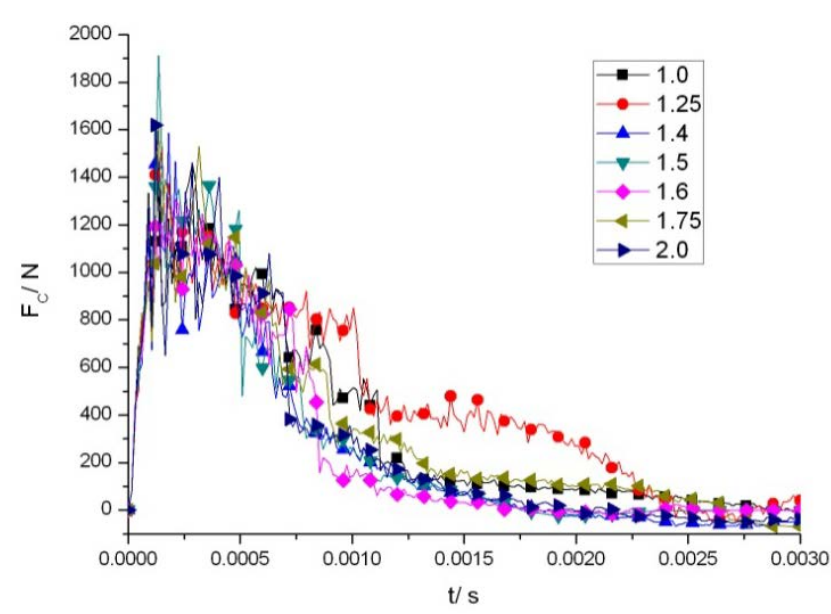

Fig.4 Contact force histories curve for different cases

Fig. 4 shows the contact force histories curve for different cases. As shown in figure 4, there is an obvious peak of the contact force both for all cases, which range from $t=0.0001 \mathrm{~s}$ to $t=0.0003 \mathrm{~s}$. Obviously, this is due to the initial contact between the bullet and the laminates. Namely it is produced when the bullet is in contact with the upper layer of the laminates. And then after the peak, the contact force gets smaller, which caused by the laminates near the contact area begins to destroy, and the stiffness of the laminates near the contact area is rapidly degraded. As the bullet goes further along the thickness, the carbon fiber laminates in the impact area were punctured through, which makes the contact force continuously decreases. As shown in figure 4, this is because the laminates is penetrated when $t>0.001 \mathrm{~s}$. A lot of bullet kinetic energy is consumed due to the deformation and destruction of laminated plates, and the contact force is even smaller. From figure 4 , it can be seen, in the impact process, the bullet has the maximum contact force at the peak contact force under Stre/Stre ${ }_{0}=1.5$, while the contact force under other cases may be greater than that under pressure/stre $_{0}=1.5$ in other phases. In general, the strength of the layer directly affects the contact force of the punching head, and the impact response characteristics of the laminates are significantly changed.

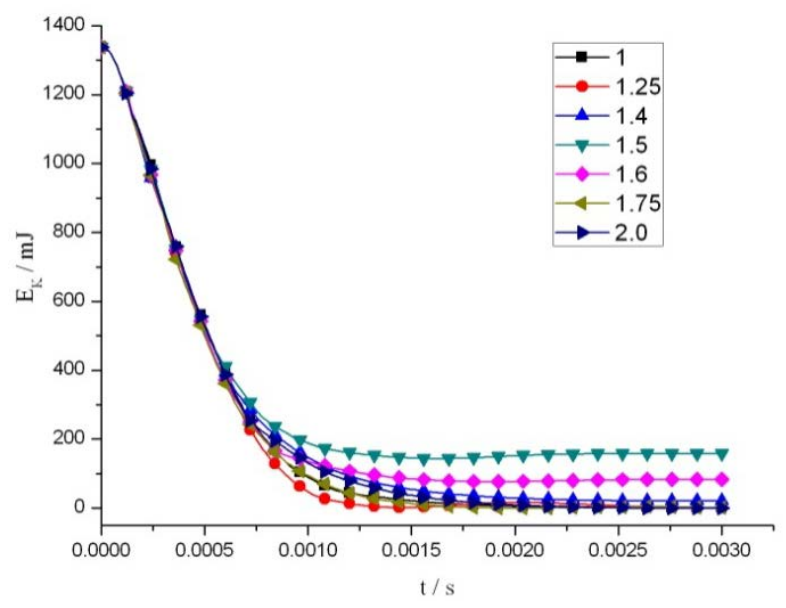

Fig.5 Kinetic energy histories curve for different cases 


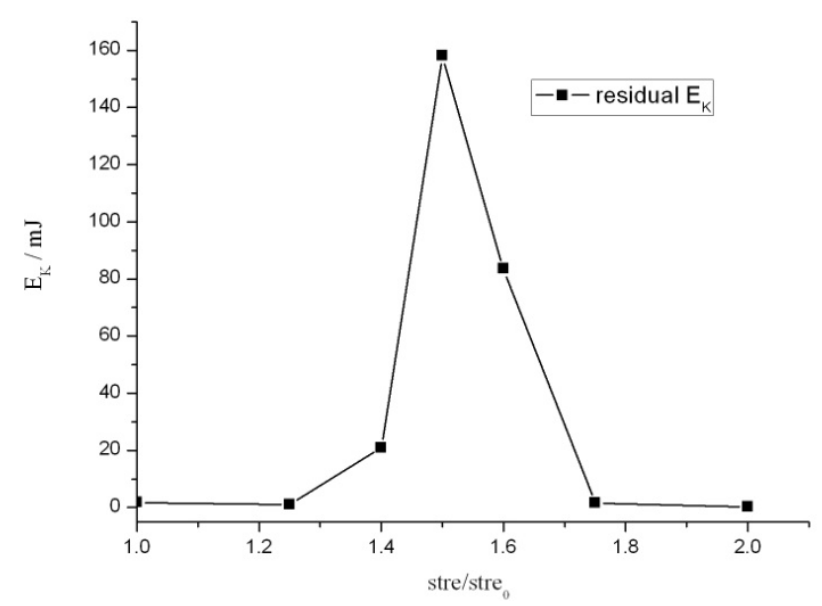

Fig.6 Residual kinetic energy for different cases

Fig. 5 shows the kinetic energy histories curve for different cases. Fig. 6 shows the residual kinetic energy for different cases. From figure 5, there is a significant difference in the kinetic energy of the bullet under the different layers strength cases. That is to say, the strength of the interface phase directly influences the dissipation of the kinetic energy of the bullet in the impact process. As shown in figure 6, when the Stre/Stre0 range from 1.0 to 1.5, with increasing of the strength of the interface phase, the residual kinetic energy of the bullet becomes lager and the kinetic energy absorption of the target plate becomes small. When the Stre/Stre ${ }_{0}$ range from 1.5 to 2.0, with increasing of the strength of the interface phase, the residual kinetic energy of the bullet becomes small and the kinetic energy absorption of the target plate becomes lager. When the Stre/Stre ${ }_{0}=1.5$, the residual kinetic energy of the bullet is maximal, and the target plate has the smallest amount of energy absorbed by the bullet. Obviously, the kinetic energy dissipation of the bullet is different from the strength of the interface phase. That is to say, the impact kinetic absorption characteristics of laminated plates are changed sharply by the interface strength.

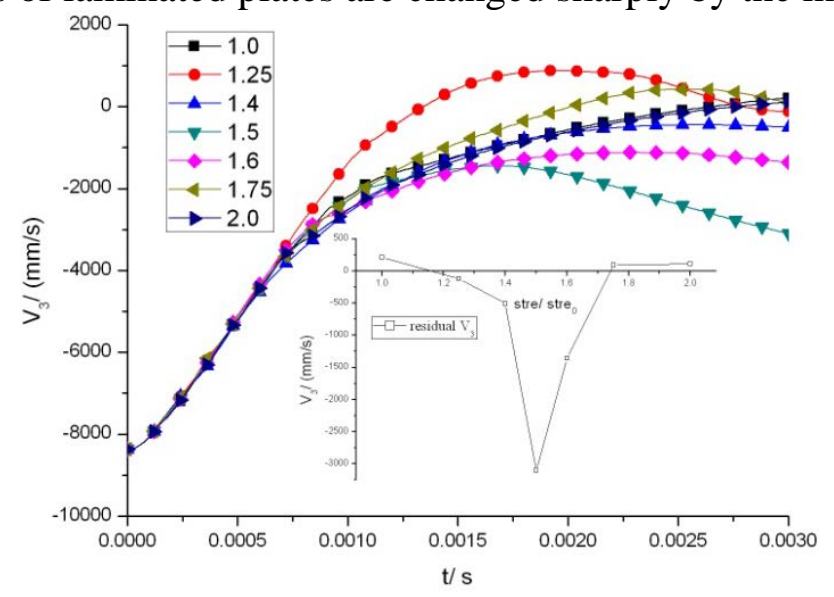

Fig.7 Velocity along the thickness direction histories curves for different cases

Fig.7 shows the velocity along the thickness direction histories curve for different cases. It can be seen that the velocity along the thickness direction histories curves present significant difference for different cases. It also can be seen that the targets have been penetrated under the conditions of Stre/Stre ${ }_{0}=1.0,1.75$ and 2.0, and the residual velocity is tiny; while the targets have not been penetrated under the conditions of Stre/Stre ${ }_{0}=1.25,1.4,1.5$ and 2.0, and the bullet rebounds. This is because the velocity of the bullet goes down to zero due to the resistance of the target in the impact process. At this point, the kinetic energy of the bullet is mostly dissipated by the failure of the laminates, and a small amount of kinetic energy is converted into the elastic strain energy of laminates. When the velocity of the bullet is zero and does not penetrate the target, the target will release its elastic strain energy, and put an anti-force on the bullet so that the bullet moves in the

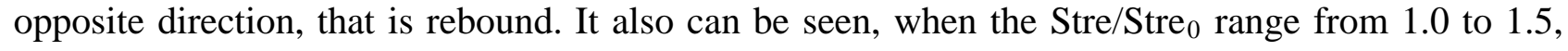


the resistance performance of laminated plate is enhanced, and the elastic strain can be increased as the interface strength increases. When the Stre/Stre $e_{0}$ ranges from 1.5 to 2.0, the resistance performance of laminated plate is weakened, and the elastic strain can be reduced as the interface strength increases. That is, the strength of the interface phase directly affects the elastic strain energy of the laminated plate and the kinetic energy dissipation of the bullet in the impact process. Namely, the transformation of the bullet kinetic energy is significantly affected during the impact process.

\section{Conclusions}

In order to study the dynamic response characteristics and the interlayer surface strength effects in carbon/epoxy composite laminates subjected to low-velocity impact load, based on Abaqus finite element software, the 3D progressive damage analysis-based user material subroutine and surface based cohesive behavior are introduced to simulate the dynamic response process of the carbon/epoxy composite laminates subjected to low-velocity impact load under different interlayer surface strength conditions. Some conclusions are drawn.

(1) The impact dynamic response of composite laminated plates is a process of stress waves (including compressive stress wave, tensile stress wave) propagation and mutual interference. The penetration is also a failure process under the action of stress waves. When Stre/Stre $0=1.0 \sim 1.5$, With the interlayer surface strength of carbon/epoxy composite laminates increase, the residual kinetic energy of bullet increases and the kinetic energy absorption of target plate decreases; When Stre/Stre0=1.5 2.0, With the interlayer surface strength of carbon/epoxy composite laminates increase, the residual kinetic energy of bullet decreases and the kinetic energy absorption of target plate increases. Obviously, the kinetic energy dissipation of bullet varies depending on the interlayer surface strength of carbon/epoxy composite laminates. That is to say, the interlayer surface strength changes the kinetic energy absorbing performance of carbon/epoxy composite laminates.

(2) The interlayer surface strength of laminates directly impacts of the elastic strain energy carbon/epoxy composite and the kinetic energy dissipation of bullet in laminates failure. Namely, the transformed form of the bullet kinetic energy is affected by the interlayer surface strength significantly.

(3)The carbon/epoxy composite laminates produce different damage states under different interlayer surface strength conditions. The interlayer surface strength presents a significant role on whether the failure form, the contact force, the kinetic energy dissipation process, the elastic strain energy composite laminates or the kinetic energy dissipation of bullet in laminates failure during the impact process.

\section{Acknowledgements}

This paper is funded by Beijing Spacecrafts. The authors acknowledge China Academy of Space Technology.

\section{References}

[1] Bajpai, V., Singh, R. (2013) Brittle damage and interlaminar decohesion in orthogonal micromachining of pyrolytic carbon.International Journal of Machine Tools \& Manufacture, 64:2030 .

[2] Zhang, J., Zhang, X. (2015) Simulating low-velocity impact induced delamination in composites by a quasi-static load model with surface-based cohesive contact. Composite Structures, 125:51-57.

[3]Aymerich F, Dore F, Priolo P. (2008) Prediction of impact-induced delamination in cross-ply composite laminates using cohesive interface elements. Composites Science and Technology, 68:2383-90. 
[4] Zhao, Y. Xing, Y., Lei, Z., Lang, F. (2008) Interfacial stress transfer behavior of single-fiber composite under the effect of mechanical and thermal loading[J]. Acta Materiae Compositae Sinica, 25(4):187-192.

[5] Luo, Q., Tong, L. (2009) Energy release rates for interlaminar delamination in laminates considering transverse shear effects. Composite Structures, 89: 235-244.

[6] Guan, Z., Liu, D., Li, X., Li. Z. (2012) Composite interlaminar damage analysis based on cohesive elem ent. Acta Materiae Compositae Sinica, 29(2):130-134.

[7] Guo, G., Jiao, G., Pan, W. (2004) Experimental study on the interlaminar fracture toughness of composite laminate on hygrothermal conditions. Acta Materiae Compositae Sinica, 21(2):83-86.

[8]Barenblatt, G.I. (1959)The formation of equilibrium cracks during brittle fracture: General ideas and hypotheses, axially-symmetric cracks. Applied Mathematics and Mechanics, 23(3):622-636.

[9]Dugdale, D.S. (1960)Yielding of steel sheets containing slits. Journal of Mechanics of Physics and Solids, 8(2):100-104.

[10] Shchegel, G. O., Böhm, R., Hornig. A., et al. (2014) Probabilistic damage modelling of textile-reinforced thermoplastic composites under high velocity impact based on combined acoustic emission and electromagnetic emission measurements. International Journal of Impact Engineering, 69:1-10.

[11] Zhang, J., Zhang, X., (2015) Simulating low-velocity impact induced delamination in composites by a quasi-static load model with surface-based cohesive contact. Composite Structures, 125: 51-57. 